\title{
VISUALISASI PENGARUH SUDUT SERANG DAN KECEPATAN ALIRAN UDARA TERHADAP STALL AIRFOIL NACA 2415 DAN NACA 4424
}

\author{
Muhamad Royan Al Faris*, Tabah Priangkoso dan Darmanto \\ Jurusan Teknik Mesin Universitas Wahid Hasyim Semarang \\ Jl. Menoreh Tengah X/22 Sampangan Semarang 50236 \\ *Email: royanboys543@gmail.com
}

\begin{abstract}
Abstrak
Airfoil itu sendiri adalah suatu bentuk geometri yang apabila ditempatkan di suatu aliran fluida akan memproduksi gaya angkat (lift) lebih dari gaya hambatan (drag). Penelitian ini bertujuan untuk memvisualisasi aliran udara melewati airfoil dan pengaruh sudut serang terhadap aliran udara. Jenis airfoil yang di gunakan adalah NACA 2415 dan NACA 4424 dengan sudut serang $0^{\circ}, 5^{\circ}, 10^{\circ}, 15^{\circ}$, $20^{\circ}, 25^{\circ}, 30^{\circ}, 35^{\circ}$, dan $40^{\circ}$ dan dengan kecepatan aliran udara $1.0 \mathrm{~m} / \mathrm{s}, 1.5 \mathrm{~m} / \mathrm{s}$, dan $2.0 \mathrm{~m} / \mathrm{s}$. Hasil visualisasi memperlihatkan semakin besar sudut serang airfoil maka vortex yang terjadi semakin besar dan wake yang terjadi lebih panjang ke belakang menjauhi airfoil dan di ikuti dengan peningkatan drag yang semakin besar semakin besar kecepatan aliran udara yang melewati airfoil maka separasi akan mulai terlihat pada sudut serang yang paling kecil. semakin besar ukuran airfoil dengan seri yang sama maka semakin besar kecepatan aliran udara yang dibutuhkan
\end{abstract}

Kata Kunci: airfoil, sudut serang, stall.

\section{PENDAHULUAN}

Dalam dunia penerbangan khususnya pesawat terbang mulai mengalami perkembangan yang tidak lepas dari berbagai penelitian yang telah dilakukan. Salah satu fokus dari penelitian yang dilakukan dalam dunia penerbangan adalah penelitian tentang airfoil. Airfoil atau sering kali dikenal dengan nama Aerofoil merupakan hal yang penting dipelajari dalam ilmu tentang aerodinamika. Airfoil itu sendiri adalah suatu bentuk geometri yang apabila ditempatkan di suatu aliran fluida akan memproduksi gaya angkat (lift) lebih dari gaya hambat (drag) (Sarjito, 2010). Jenis airfoil yang biasa di gunakan dalam dunia penerbangan adalah airfoil jenis tidak simetris. Jenis airfoil tidak simetris memiliki geometri dengan karakteristik aerodinamika yang dapat meningkatkan nilai koefisien lift pada pesawat terbang. Perbandingan airfoil simetris dengan airfoil tidak simetris maka akan mendapatkan hasil bahwa koefisien lift pada airfoil tidak simetris lebih tinggi dari pada airfoil simetris (Wei Zhang, 2015).

Dalam membuat dan menyelidiki kinerja airfoil harus dilakukan dengan cobacoba, karena setiap kali pengubahan model sering kali banyak bahan terbuang dan harus memproduksi model baru terlebih dahulu untuk melakukan penyelidikan selanjutnya. (Sarjito, 2010).

\section{SUDUT SERANG}

Sudut serang atau biasa dikenal dengan istilah angle of attack adalah Tali busur sebuah airfoil dan arah aliran udara yang membentuk sebuah sudut dan diberi notasi $(\alpha)$. Sudut serang itu sendiri dibagi menjadi dua jenis yaitu sudut serang mutlak dan sudut serang kritis. Sudut serang mutlak adalah sudut yang diukur dari keadaan zero angle lift. Sudut serang kritis yaitu sudut serang yang menghasilkan gaya angkat yang mendekati maksimum (Ramadika \& Permatasari, 2018)

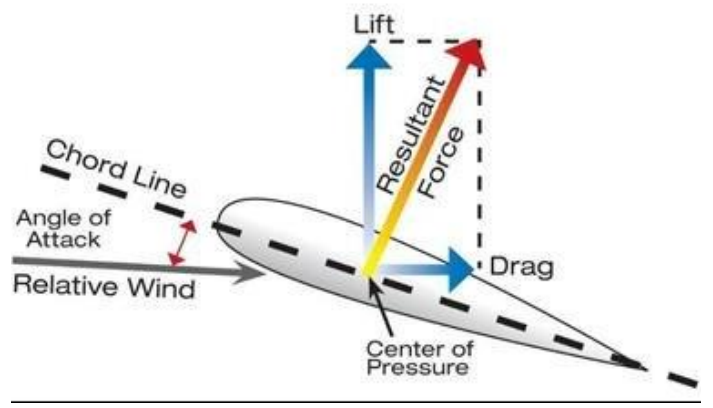

Gambar 1. Posisi sudut serang (angle of attack) (Kabir, 2019)

Salah satu yang harus diperhatikan bahwa airfoil memiliki kelemahan yang biasa disebut dengan Stalling Angle Of Attack. Stall itu sendiri dapat dipahami sebagai fenomena ketika sudut serang sangat besar atau kecepatan aliran terlalu besar sehingga udara tidak bisa mengalir secara laminar. Aliran 
udara tidak bisa menyentuh bagian belakang sudu sehingga terjadi separasi aliran bagian belakang sudu. Situasi ini signifikan menurunkan gaya lift dan meningkatkan gaya drag (Satrio dkk., 2015).

\section{STALL}

Stall terjadi ketika kecepatan aliran terlalu besar sehingga udara tidak bisa mengalir secara laminar atau bisa dipahami sebagai fenomena ketika sudut serang sangat besar. Ciri-ciri stall adalah ketika aliran udara tidak bisa menyentuh bagian belakang sudu sehingga terjadi separasi aliran bagian belakang sudu. Situasi ini signifikan menurunkan gaya angkat (lift) dan meningkatkan gaya hambat (drag) (Satrio dkk., 2015). Untuk lebih jelasnya dapat dilihat ilustrasi Gambar II.9.

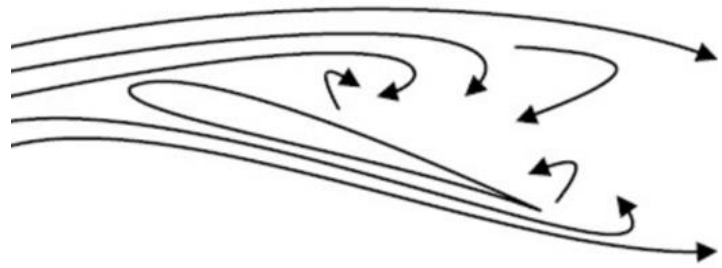

Gambar 2. Fenomena stall menyebabkan separasi aliran udara (Satrio dkk., 2015).

Visualisasi aliran bertujuan untuk membantu menganalisis bagaimana fenomena aliran melintasi sebuah airfoil yang nantinya bisa mendukung data yang didapat dari pengambilan data secara eksperimental, seperti terjadinya separasi, vortex dan proses terjadinya stalling.

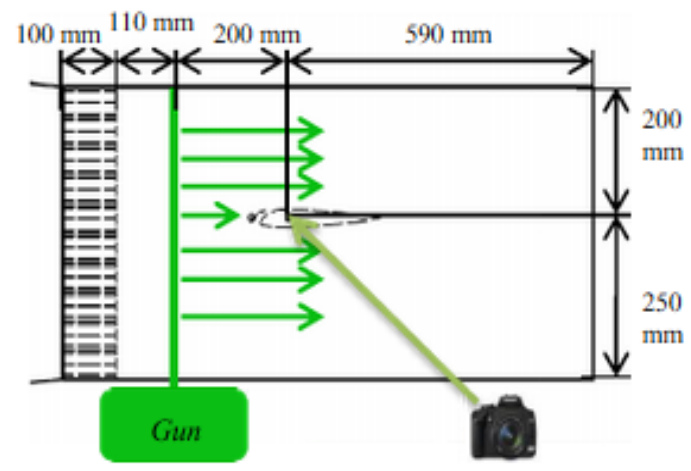

Gambar 3. Skema pengamatan visualisasi dengan asap (Mariasa, 2013)
Pada skema pengamatan visualisasi aliran udara yang melewati airfoil yang di tunjukan pada Gambar 3 ini dimana Garisgaris hijau dengan arah ke kanan menunjukkan aliran udara yang melewati airfoil. Asap yang dihasilkan dialirkan bersama dengan udara melewati airfoil yang di uji sehingga memudahkan peneliti dalam melakukan pengamatan fenomena yang terjadi Dan asap yang di pakai dalam penelitian ini adalah menggunakan obat nyamuk spiral. Kamera berfungsi dalam pengambilan video visualisasi yang kemudian di konversi menjadi foto (Mariasa, 2013).

\section{METODE}

Jenis airfoil yang digunakan pada pengujian ini adalah NACA 2415 dan NACA 4424 menggunakan variabel diantaranya adalah sudut serang $0^{\circ}, 5^{\circ}, 10^{\circ}, 15^{\circ}, 20^{\circ}, 25^{\circ}$, $30^{\circ}, 35^{\circ}$, dan $40^{\circ}$ dengan kecepatan udara 1.0 $\mathrm{m} / \mathrm{s}, \quad 1.5 \mathrm{~m} / \mathrm{s}$, dan $2.0 \mathrm{~m} / \mathrm{s}$. Pengujian dilaksanakan di Laboratorium Energi Program Studi Teknik Mesin Fakultas Teknik Universitas Wahid Hasyim Semarang.

Pada spesimen yang telah dibuat adalah menggunakan kayu balsa, dan standar bentuk yang digunakan dalam pengujian adalah airfoil NACA 2415 dan airfoil NACA 4424 yang bisa dilihat pada Gambar 4 .

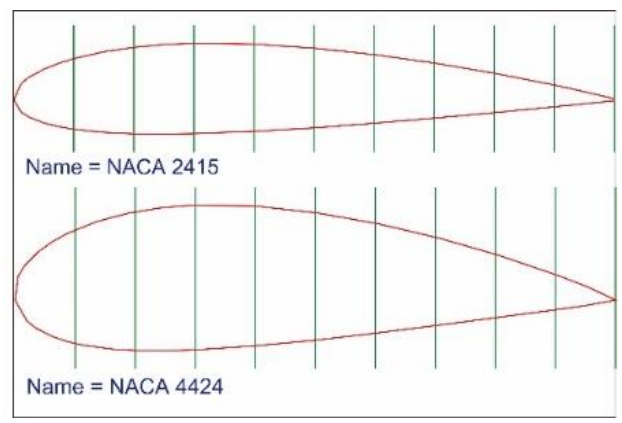

Gambar 4. Standar Airfoil NACA 2415 dan

NACA 4424 (http://airfoiltools.com/2

Seri airfoil pada Gambar 4. ini adalah seri NACA 4 digit dengan jenis airfoil tidak simetris dan biasanya di aplikasikan pada General aviation, Horizontal tails.

Langkah-langkah penelitian seperti yang ditunjukkan Gambar 5. 


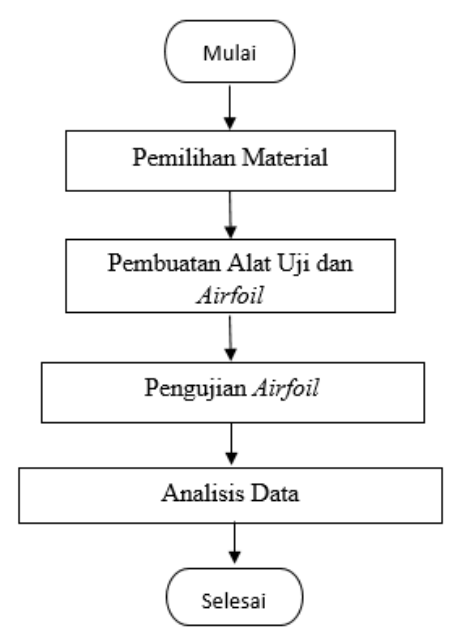

Gambar 5. Langkah-langkah Penelitian

\section{HASIL DAN PEMBAHASAN}

Hasil Visualisasi

1. Airfoil NACA 2415 pada kecepatan aliran udara $1,0 \mathrm{~m} / \mathrm{s}$ untuk berbagai sudut serang.

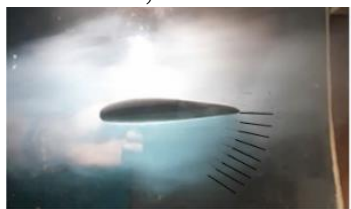

(a) Sudut serang $0^{\circ}$

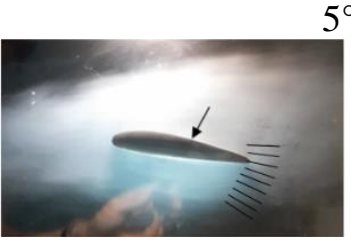

(c) Sudut serang $10^{\circ}$

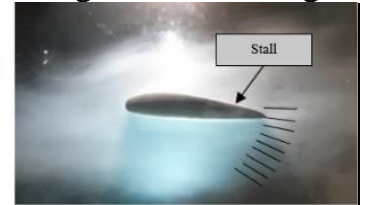

(b) Sudut serang

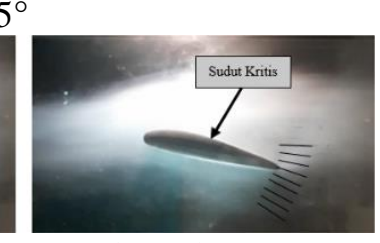

$15^{\circ}$

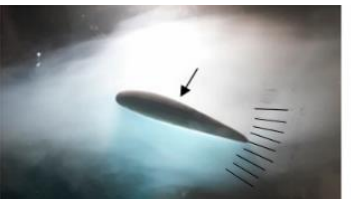

(e) Sudut serang $20^{\circ}$

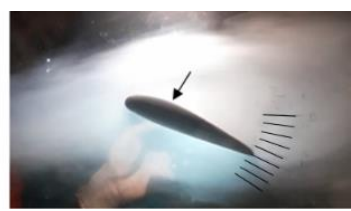

(f) Sudut serang

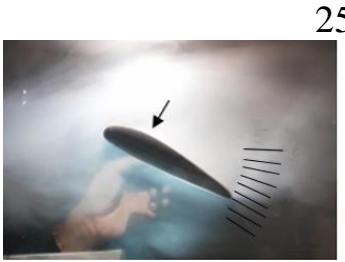

(g) Sudut serang $30^{\circ}$

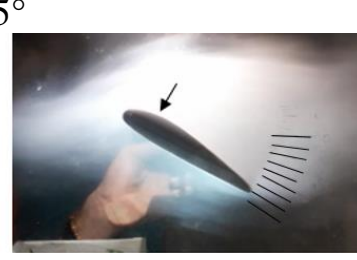

(h) Sudut serang

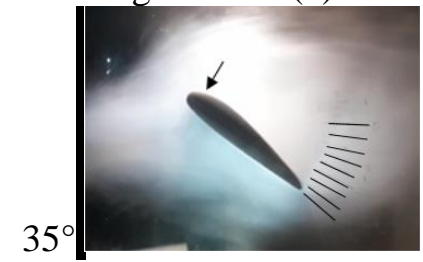

(i) Sudut serang $40^{\circ}$

Gambar 6. Airfoil 2415 pada Kecepatan 1,0 $\mathrm{m} / \mathrm{s}$
Dari gambar 3 terlihat separasi yang ditunjukan oleh anak panah terjadi pada sudut serang $5^{\circ}$ dan di sudut inipun airfoil sudah mulai mengalami stall. Sedangkan sudut serang kritis terlihat pada sudut $15^{\circ}$ karena separasi terjadi jauh di depan mendekati leading edge sehingga terjadi tekanan yang sangat rendah pada sisi upper side dan fluida bergerak dengan cepat mengisi sisi yang bertekanan rendah tersebut.

2. Airfoil NACA 2415 pada kecepatan arus angin $1,5 \mathrm{~m} / \mathrm{s}$ untuk berbagai sudut serang.

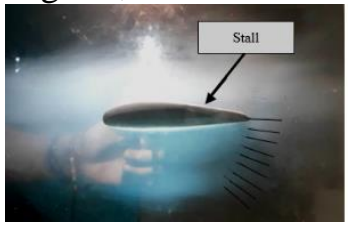

(a) Sudut serang $0^{\circ}$

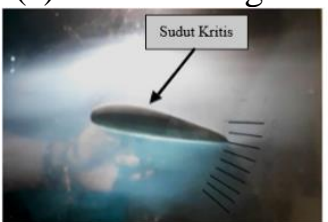

(c) Sudut serang $10^{\circ}$

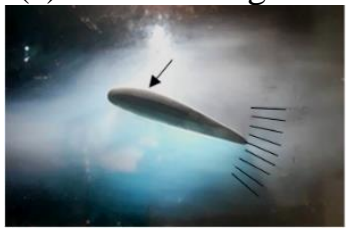

(e) Sudut serang $20^{\circ}$

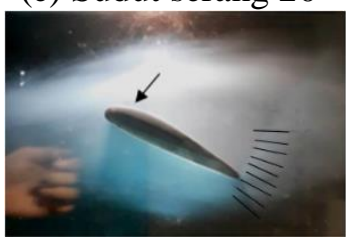

(g) Sudut serang $30^{\circ}$

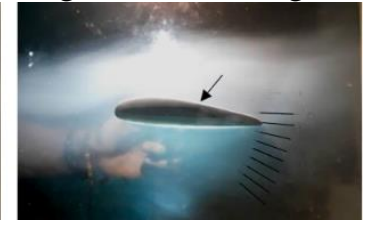

(b) Sudut serang $5^{\circ}$

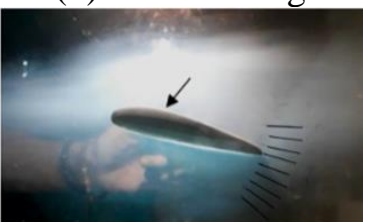

(d) Sudut serang $15^{\circ}$

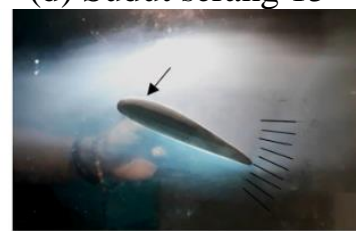

(f) Sudut serang $25^{\circ}$

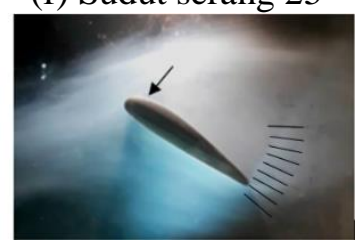

(h) Sudut serang 35

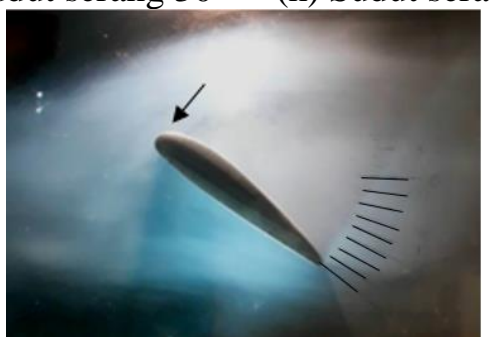

(i) Sudut serang $40^{\circ}$

\section{Gambar 7. Airfoil NACA 2415 pada Kecepatan 1,5 m/s}

Dari gambar 4 terlihat separasi dimana aliran udara tidak bisa menyentuh bagian belakang sudu yang ditunjukan oleh anak panah terjadi pada sudut serang $0^{\circ}$ dan di sudut inipun airfoil sudah mulai mengalami stall, sedangkan sudut serang kritis terlihat 
pada sudut $10^{\circ}$. Dengan demikian terlihat perbedaan hasil dimana hasil pengujian pada Gambar 4 terlihat separasi muncul lebih awal di banding dengan hasil yang di tunjukan pada Gambar 3.

\section{Airfoil NACA 2415 pada kecepatan arus} angin $2.0 \mathrm{~m} / \mathrm{s}$ untuk berbagai sudut serang.

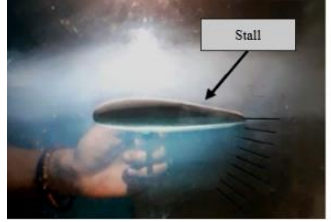

(a) Sudut serang $0^{\circ}$ $5^{\circ}$

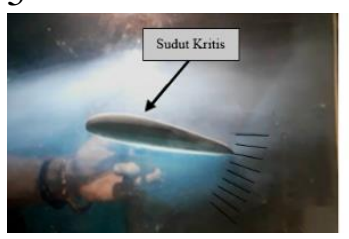

(c) Sudut serang $10^{\circ}$ $15^{\circ}$

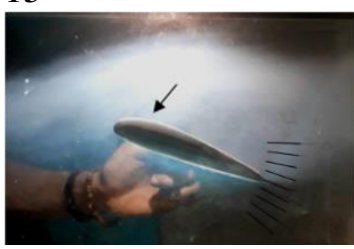

(e) Sudut serang $20^{\circ}$ $25^{\circ}$

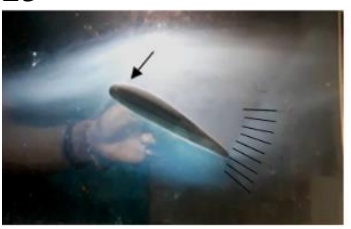

(g) Sudut serang $30^{\circ}$

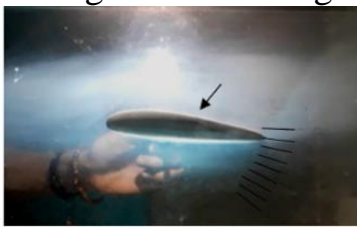

(b) Sudut serang

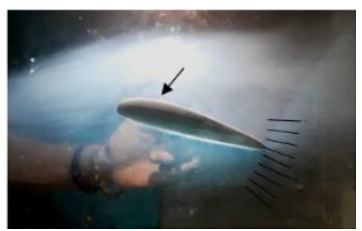

(d) Sudut serang

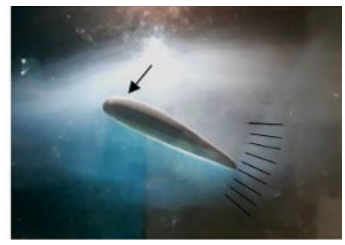

(f) Sudut serang

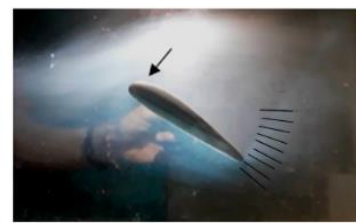

(h) Sudut serang

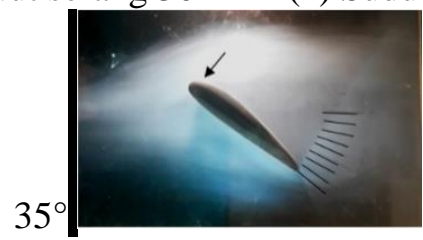

(i) Sudut serang $40^{\circ}$

Gambar 8. Airfoil NACA 2415 pada Kecepatan 2,0 m/s

Dari Gambar 5 terlihat separasi dimana aliran udara tidak bisa menyentuh bagian belakang sudu yang ditunjukan oleh anak panah terjadi pada sudut serang $0^{\circ}$ dan di sudut inipun airfoil sudah mulai mengalami stall, sedangkan sudut serang kritis terlihat pada sudut $10^{\circ}$. Hasil disini memungkinkan sudut serang kritis terjadi pada sudut di antara $5^{\circ}$ dan $10^{\circ}$ karena di sudut $5^{\circ}$ separasi sudah hampir mendekati sudut serang kritis.
4. Airfoil NACA 4424 pada kecepatan arus angin $1,0 \mathrm{~m} / \mathrm{s}$ untuk berbagai sudut serang.

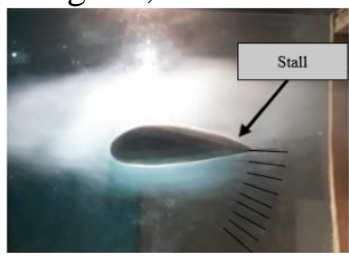

(a) Sudut Serang $0^{\circ}$ $5^{\circ}$

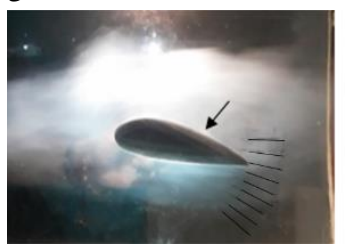

(c) Sudut serang $10^{\circ}$ $15^{\circ}$

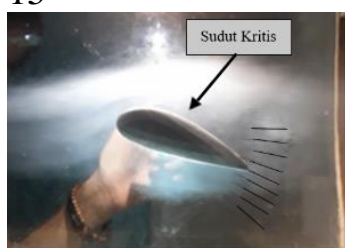

(e) Sudut serang $20^{\circ}$ $25^{\circ}$

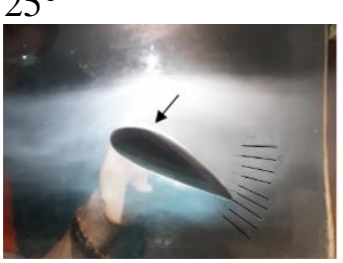

(g) Sudut serang $30^{\circ}$

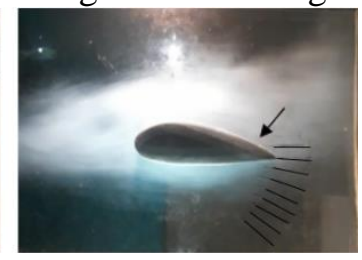

(b) Sudut Serang

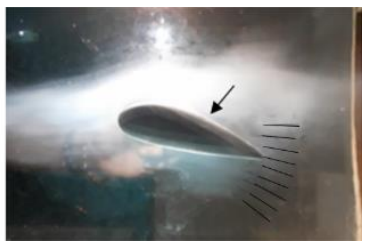

(d) Sudut serang

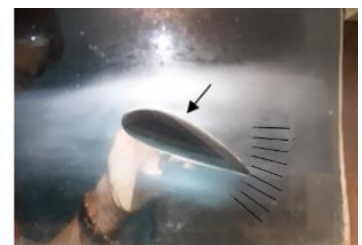

(f) Sudut serang

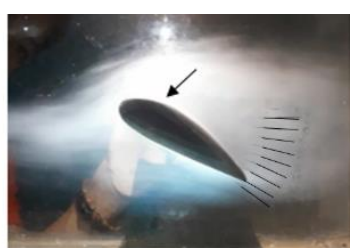

(h) Sudut serang $35^{\circ}$

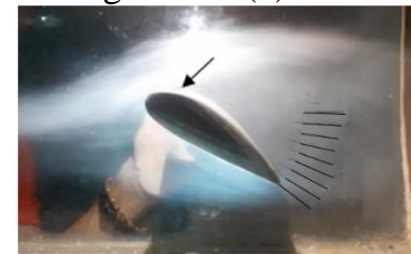

(i) Sudut serang $40^{\circ}$

Gambar 9. Airfoil 4424 pada Kecepatan 1,0 $\mathrm{m} / \mathrm{s}$

Dari Gambar 6 terlihat separasi yang ditunjukan oleh anak panah terjadi pada sudut serang $0^{\circ}$ dan di sudut inipun airfoil sudah mulai mengalami stall. Sedangkan sudut serang kritis terlihat pada sudut $20^{\circ}$ karena separasi terjadi jauh di depan mendekati leading edge sehingga terjadi tekanan yang sangat rendah pada sisi upper side dan fluida bergerak dengan cepat mengisi sisi yang bertekanan rendah tersebut.

\section{Airfoil NACA 4424 pada kecepatan arus} angin $1.5 \mathrm{~m} / \mathrm{s}$ untuk berbagai sudut serang. 


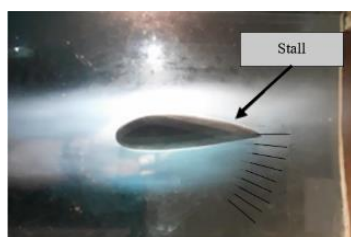

(a) Sudut Serang $0^{\circ}$

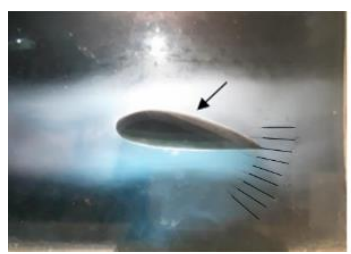

(c) Sudut serang $10^{\circ}$

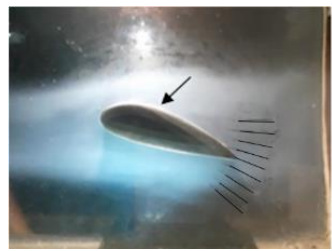

(e) Sudut serang 20

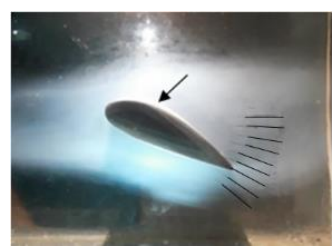

(g) Sudut serang $30^{\circ}$

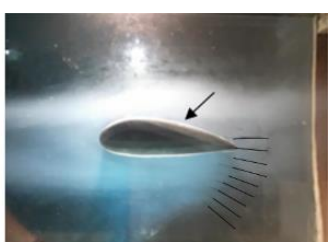

(b) Sudut Serang $5^{\circ}$

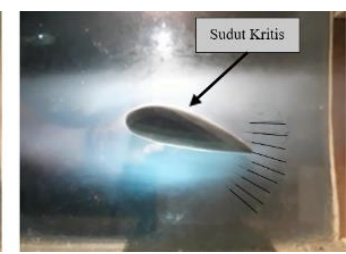

(d) Sudut serang $15^{\circ}$

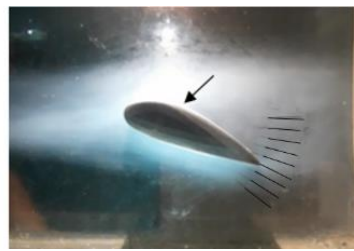

(f) Sudut serang $25^{\circ}$

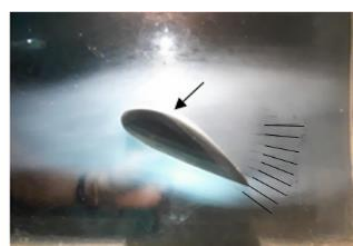

(h) Sudut serang $35^{\circ}$

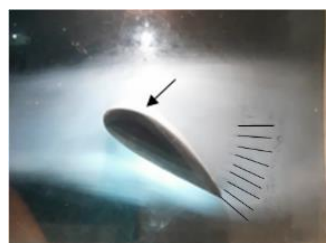

(i) Sudut serang $40^{\circ}$

\section{Gambar 10. Airfoil NACA 4424 pada Kecepatan 1,5 m/s}

Dari gambar 7 terlihat separasi dimana aliran udara tidak bisa menyentuh bagian belakang sudu yang ditunjukkan oleh anak panah terjadi pada sudut serang $0^{\circ}$ dan di sudut inipun airfoil sudah mulai mengalami stall, sedangkan sudut serang kritis terlihat pada sudut $15^{\circ}$. Dengan demikian terlihat perbedaan hasil dimana hasil pengujian pada Gambar 7 terlihat sudut serang kritis terjadi lebih awal di banding dengan hasil yang di tunjukan pada Gambar 6.

6. Airfoil NACA 4424 pada kecepatan arus angin $2.0 \mathrm{~m} / \mathrm{s}$ untuk berbagai sudut serang.

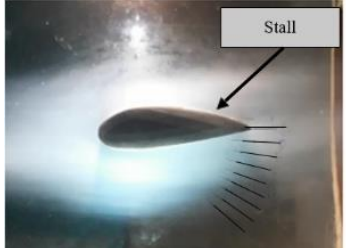

(a) Sudut Serang $0^{\circ}$

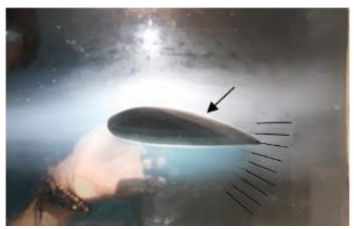

(c) Sudut serang $10^{\circ}$

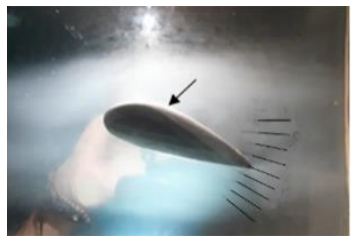

(e) Sudut serang $20^{\circ}$

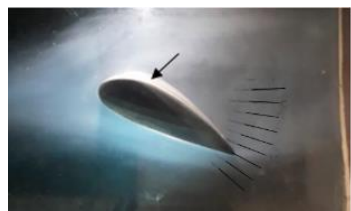

(g) Sudut serang $30^{\circ}$

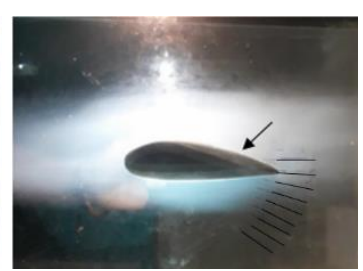

(b) Sudut Serang $5^{\circ}$

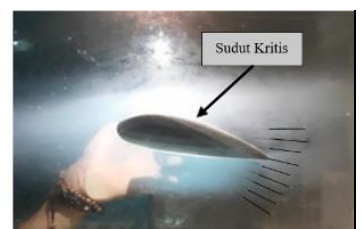

(d) Sudut serang $15^{\circ}$

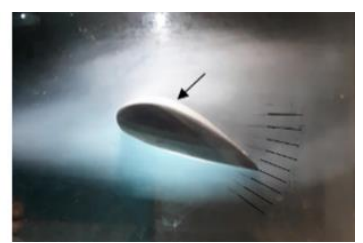

(f) Sudut serang $25^{\circ}$

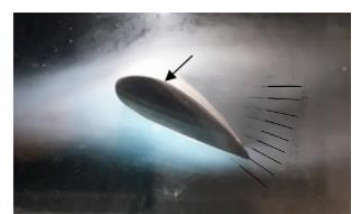

(h) Sudut serang $35^{\circ}$

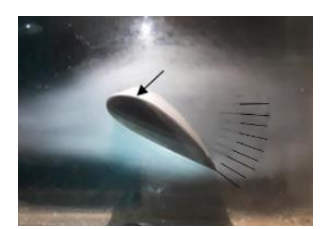

(i) Sudut serang $40^{\circ}$

\section{Gambar 11. Airfoil NACA 4424 pada} Kecepatan 2,0 m/s

Dari gambar 8 terlihat separasi yang ditunjukkan oleh anak panah terjadi pada sudut serang $0^{\circ}$ dan di sudut inipun airfoil sudah mulai mengalami stall. Sedangkan sudut serang kritis terlihat pada sudut $15^{\circ}$

\section{Tabel 1 Terjadinya Sudut Serang Kritis Dan} Stall

\begin{tabular}{cccc} 
Airfoil & $\begin{array}{c}\text { Kecepatan } \\
\text { Aliran } \\
(\mathrm{m} / \mathrm{s})\end{array}$ & \multicolumn{2}{c}{ Sudut Serang $(\alpha)$} \\
\cline { 3 - 4 } & 1 & Stall & Sudut Kritis \\
\hline \multirow{2}{*}{ NACA } & 1,5 & $5^{\circ}$ & $15^{\circ}$ \\
2415 & 2 & $0^{\circ}$ & $10^{\circ}$ \\
& 1 & $0^{\circ}$ & $10^{\circ}$ \\
\hline \multirow{2}{*}{ NACA } & 1,5 & $0^{\circ}$ & $10^{\circ}$ \\
4424 & 2 & $0^{\circ}$ & $15^{\circ}$ \\
& & &
\end{tabular}


Pada tabel IV.1 Airfoil NACA 2415 dengan kecepatan aliran 1,0 m/s pada sudut serang $0^{\circ}$ belum mengalami stall sedangkan airfoil NACA 4424 sudah mengalami stall yang di tandai dengan adanya separasi yang terjadi di upper side. NACA 2415 mengalami sudut serang kritis lebih awal dari pada airfoil 4424 di tandai dengan adanya separasi yang terjadi jauh di depan mendekati leading edge. jika dilihat pada Tabel 1 semakin cepat aliran udara maka separasi akan muncul lebih awal pada sudut terendah.

Dari hasil visualisasi NACA 2415 sudut mutlak terjadi pada sudut serang $40^{\circ}$ karena terlihat dengan jelas separasi terjadi lebih awal dekat mendekati leading egde menyebabkan terbentuknya vortex yang sangat besar dan terjadi back pressure pada upper side. Fenomena seperti ini sering disebut dengan stalling angle of attack dimana gaya angkat yang dihasilkan oleh airfoil akan berkurang dan sebaliknya gaya hambat/drag akan bertambah besar yang efeknya sangat merugikan. Pada sudut yang lebih besar vortex yang terjadi semakin besar dan wake yang terjadi lebih panjang ke belakang menjauhi airfoil dan di ikuti dengan peningkatan drag yang semakin besar. Pada hasil $10^{\circ}$ NACA 2415 hasil sudut kritis ini mirip dengan Araque dan Nozicka (2012) dalam pengujiannya mendapatkan hasil bahwa airfoil NACA 2415 mengalami sudut serang kritis pada sudut $9^{\circ}$ dengan kecepatan aliran $7,7 \mathrm{~m} / \mathrm{s}$. Hasil pengujian terdahulu dengan hasil yang terpapar pada Tabel 1 hampir sama pada kecepatan aliran $1,5 \mathrm{~m} / \mathrm{s}$ dan $2,0 \mathrm{~m} / \mathrm{s}$, dengan selisih $1^{\circ}$ padahal peneliti terdahulu menggunakan kecepatan aliran yang lebih besar dari pada penelitian kali ini. Penyebab utamanya bisa karena ukuran airfoil pada penelitian terdahulu lebih besar dari pada penelitian kali ini yaitu dengan panjang chord $200 \mathrm{~mm}$ dan Span $600 \mathrm{~mm}$.

Dari hasil visualisasi NACA 4424 sudut mutlak terjadi pada sudut serang $40^{\circ}$ karena terlihat dengan jelas separasi terjadi lebih awal dekat mendekati leading egde menyebabkan terbentuknya vortex yang sangat besar dan terjadi back pressure pada upper side. Fenomena seperti ini sering disebut dengan stalling angle of attack dimana gaya angkat yang dihasilkan oleh airfoil akan berkurang dan sebaliknya gaya hambat/drag akan bertambah besar yang efeknya sangat merugikan. Pada sudut yang lebih besar vortex yang terjadi semakin besar dan wake yang terjadi lebih panjang ke belakang menjauhi airfoil dan di ikuti dengan peningkatan drag yang semakin besar. Pada hasil $15^{\circ}$ NACA 4424 hasil sudut kritis ini mirip dengan hasil pengujian Sikien dkk. (2018) yang meneliti NACA 4424 dengan mendapat hasil bahwa airfoil mengalami sudut serang kritis $15^{\circ}$ dengan kecepatan aliran $14.6073 \mathrm{~m} / \mathrm{s}$. Kemungkinan bisa mendapat hasil yang sama dengan hasil penelitian yang terpapar pada Tabel 1 yaitu bisa jadi karena perbedaan ukuran dimana peneliti terdahulu memilih ukuran yang lebih besar dari penelitian kali ini. Karena dalam penelitian terdahulu NACA 4424 tidak di paparkan ukuran airfoil maka peneliti kali ini menyimpulkan dengan menyamakan hasil perbandingan dengan hasil NACA 2415.

\section{KESIMPULAN}

1. semakin besar sudut serang airfoil maka vortex yang terjadi semakin besar sehingga wake yang terjadi lebih panjang ke belakang menjauhi airfoil yang mengakibatkan peningkatan drag yang semakin besar. NACA 4424 memiliki sudut serang kritis yang besar di bandingkan NACA 2415.

2. semakin besar kecepatan aliran udara yang melewati airfoil maka separasi akan mulai terlihat pada sudut serang yang paling kecil.

\section{DAFTAR PUSTAKA}

Asif Kabir, M. S., \& Md. Jahirul Islam, M. I. (2019). Numerical Assessment of the Backward Facing Step for NACA 0015 Airfoil using Computational Fluid Dynamics. 1st International Conference on Advances in Science, Engineering and Robotics Technology 2019 (ICASERT 2019).

Dendy Satrio, S. N. (2015). Studi Eksperimen Pengaruh Sudut Pasang Terhadap Kecepatan Putar Rotor Turbin Angin Sumbu Horizontal. Politeknik Elektronika Negeri Surabaya. Jalan Raya ITS Sukolilo, Surabaya 60111.

Kadek Gilang Mariasa, A. A. (2013). Karakteristik Airfoil Naca "00xx" Dengan Fariasi Sudut Serang. Jurnal Ilmiah Teknik Desain Mekanika Vol. 1 No. 1, Juli 2013, 61-68. 
Ramadika, W., \& Permatasari, R. (2018). Pengaruh Panjang Chord Terhadap Nilai Koefisien Gaya Angkat (Cl) Dan Koefisien Gaya Hambat (Cd) Pada Variasi Sudut Serang Hydrofoil Naca 0018 Menggunakan Computational Fluid Dynamics.

Sarjito, S. (2010). Studi Karakteristik Airfoil Naca 2410 Dan Naca 0012 Pada Berbagai Variasi Angle Of Attack. Media Mesin, Vol. 11, No. 1.

Wei Zhang, W. C. (2015). Geometrical Effects On The Airfoil Flow Separation And Transition. Computers \& Fluids, 60-73. 